\title{
A decomposition analysis of inequalities in low birth weight in Sri Lanka: findings from the Demographic and Health Survey - 2016
}

\author{
Gayathri Abeywickrama', Chamara Anuranga ${ }^{2}$ \\ (Index words: low birth weight, Inequalities, concentration index, decomposition)
}

\begin{abstract}
Birth weight is a crucial indicator of mothers and infants nutritional status. It determines a newborn's likelihood of survival, their growth and their psychological development. This study examines the socio-economic inequalities of low birth weight in Sri Lanka using the first island-wide Demographic and Health Survey (DHS) conducted in 2016 . Nearly $17 \%$ of babies are reported as low birth weight (LBW) and the prevalence has stagnated for nearly two decades in Sri Lanka. LBW is indicative of inequalities in particular population subgroups.

There is a lack of research on LBW inequalities and the contribution of different socio-economic determinants to these inequalities in Sri Lanka. A stepwise multivariate linear regression, health inequality measures and decomposition method are used to examine inequalities in LBW. Maternal body mass index (BMI), height, antenatal visits, birth interval, wealth and ethnicity are significantly associated with mean birth weight. Findings reveal that inequalities exist, where LBW is concentrated among the poorest households. The decomposition results highlight maternal BMI, education and ethnicity as major contributing factors for such inequalities. These findings suggest prioritising the nutritional needs of mothers and relevant interventions to address inequalities in birth weight to reduce the stagnated LBW in Sri Lanka.
\end{abstract}

Ceylon Medical Journal 2020; 65: 15-22

DOI: http://doi.org/10.4038/cmj.v65i1-2.9132

\section{Introduction}

Birth weight is a crucial indicator for determining a newborn's likelihood of survival, growth, long-term health and psychological development $[1,3]$. The proportion of babies born with a low birth weight ( LBW) defined as a birth weight below 2500 grams, remains a significant global health concern [1,2]. Babies born with LBW face both short and long-term adverse consequences, including higher probabilities of infection, disability during childhood, problems related to behavior and learning during childhood [3-6]. Furthermore, LBW may result in a high incidence of diseases, impaired cognitive development and increased adulthood risks of non-communicable diseases (NCDs) [7]. Reducing LBW is one of the global nutrition target which is crucial in achieving the Sustainable Development Goals for health [8].

Many contributing factors have been postulated to determine the birth weight of a newborn. These diverse factors are grouped into categories such as maternal and socioeconomic factors. These categories can be identified such as maternal age, maternal body mass index (BMI), maternal nutrition, pregnancy intervals, gestational age, smoking and alcohol consumption, educational level and economic status, etc. [9-14].

Sri Lanka has been acknowledged globally for its remarkable achievements in health, namely low child, infant and maternal mortality rates and increased life expectancy [15-17]. However, nutrition related indicators have failed to show significant progress over the last decade (2006-2016). Recent data suggests that LBW fluctuated between 16 and 17\% from 2005/2006 to 2015/ 2016 [18]. LBW rates across the districts were considered during 2006 and 2016, which display significant changes (Figure 1). LBW was declined by comparable magnitudes in 10 districts; the decline was more pronounced in Nuwara Eliya, Galle, Matale and Hambantota districts. However, for some districts, proportions of LBW have increased compared to the DHS 2006. The increase was marked in 10 districts, including Puttalam and Ratnapura. These changes are highlighted in the $3^{\text {rd }}$ map of the Figure 1 . Nevertheless, the distribution in Northern Province districts remained amongst the lowest of 6-10\%. The increase of the LBW in 2016 for some districts particularly, Colombo, Gampaha and Kalutara, lead to overall LBW rate value remains high for the country.

\footnotetext{
${ }^{1}$ Senior Lecturer, Department of Demography, University of Colombo, PhD Student, University of Southampton, UK, ${ }^{2}$ Department of Geography, University of Calgary, Canada.
}

Correspondence: GA, e-mail: <gayathri@demo.cmb.ac.lk>. Received 19 August 2019 and revised version 28 May 2020 accepted 02 July 2020

This is an open-access article distributed under the terms of the Creative Commons Attribution License, which permits unrestricted use, distribution, and reproduction in any medium, provided the original author and source are credited. 

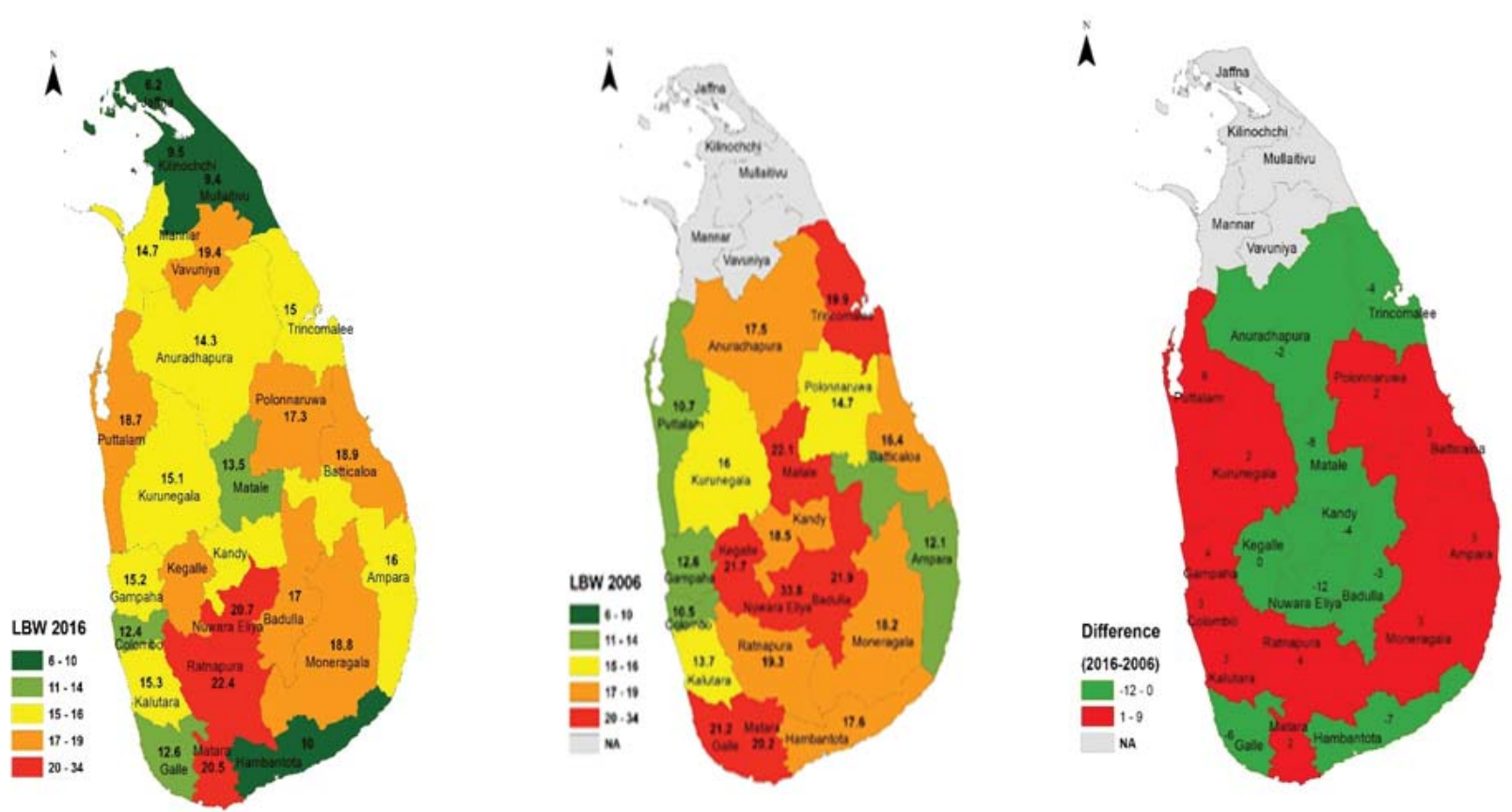

Figure 1. Low birth weight prevalence (\%) by district, DHS 2006, DHS 2016 and the difference *Due to the unavailability of DHS 2006 data. Low birth weight was graphed using $<2500$ grams for both years to maintain consistency.

The stagnant LBW rates have manifested as a substantial health and financial burden on the health sector in Sri Lanka, which is predominately based on a public health system [19]. Despite actions taken by the government, such as food/micronutrient supplementation programmes as in the National Health Policy-2011 and poverty alleviation programmes to improve the nutrition of new born babies, progress in addressing LBW is still lagging [20].

Reducing the prevalence of LBW in Sri Lanka requires a clear understanding of distribution and determinants of birth weight across sub-population who are at great risk. Further, it is important to explore socioeconomic gradient in low birth weight across population groups to target health interventions to reduce socioeconomic inequalities in low birth weight. Previous studies on LBW were conducted in specific settings (e.g., rural or hospital-based studies) in Sri Lanka and the study population of these studies were relatively small and homogeneous so the national level determinates of birth weight across the country cannot be identified. In addition, the determinants of socioeconomic inequalities and decomposing such inequalities have not been extensively studied in the context of Sri Lanka. Hence, this study uses the first nationally representative DHS 2016/2017 data after the civil war ended in 2009 in Sri Lanka. The objectives of this study are twofold: first, to identify socioeconomic determinants of birth weight; and secondly, to decompose these determinants to find out their contribution for such inequalities in low birth weight.

\section{Methodology}

Data and sample selection

This study utilises data from the 2016-2017 Sri Lankan DHS (Demographic and Health Survey). This survey is comprised of data on a nationally representative stratified clustered sample of 27,210 household units covering all 25 districts of Sri Lanka. Within the households, 18,302 ever-married women aged 15-49 were selected to collect information on childbirth and reproductive health. Total of 7,713 of birth weight records were extracted from the Child Health Development Record (CHDR) for children who were born since January 2011 (0-59 months up to the date of the interview in 2016). Data were obtained from the Department of Census and Statistics after completing essential ethical formalities. The approval complied with the data dissemination policy published by the Department of Census and Statistics in Sri Lanka

\section{Outcome variable: Birth weight}

Birth weight was used as a continuous variable in the regression model, which was converted into a binary outcome to graph concentration indexes. This study slightly overestimates low birth weight when compared to other studies, using LBW threshold of less than or equal to 2500 grams ( $<=2500 \mathrm{~g}$ ). This is due to the potentiality of heaping on birth weight data. There were 220 cases (2.6\%) reported on 2500 grams. Since the birth weight data was extracted from the health records, rounding to the approximate digit at the reporting could be expected from the current survey. Children were classified into 2 
groups: non-LBW (birth weight $>$ 2,500 grams, coded 0) or LBW (birth weight $<=2,500$ grams, coded 1 ). This analysis only considered 7,713 live, singleton births with weights ranging 400-6500 grams born to the mothers.

\section{Explanatory variables}

This study included maternal characteristics such as maternal age, BMI, height, birth interval, gestational age in months, consumption of Thriposha (Triple nutrient provided by the government for pregnant mothers), antenatal care (ANC) visits, and the sex of the child. Socioeconomic factors included the following. Maternal education classified in six categories no education, primary (1-5 grades), secondary (6-11 grades), passed GCE O/Level (General Certificate of Education Ordinary Level), passed GCEA/Level (General Certificate of Education - Advanced Level), and Degree and above. Wealth index values were used as five quintiles: lowest; second; middle; fourth; and highest. Ethnicity was grouped according to the major ethnic groups: Sinhalese, Sri Lankan Tamil, Indian Tamil, Muslim and Malay and Burgher ethnicities. Place of usual residence was classified into urban, rural and estate sectors $^{1}$. Provinces which are administratively defined into nine provinces in Sri Lanka were also considered in the study.

\section{Statistical analysis}

Stepwise multivariate linear regression analysis was used in order to determine the relative effect of each factor on birth weight. A p-value less than 0.05 were considered statistically significant. Concentration curves (CC) and concentration indexes (CI) were also used to estimate the extent of wealth-related inequality in LBW. These were further disaggregated at the residential level (urban, rural and estate). Finally, socioeconomic factors were decomposed to understand their relative contribution to the birth weight inequality. The purpose of decomposition is to examine wealth-based inequality in the determinants of low birth weight. For decomposition we used the method explained by O’Donnell et al. (2006) [21]. Decomposition estimates the contribution of each determinant to the overall inequality as the product of the sensitivity (elasticity) of birth weight to understand the degree of inequality in the variable. In simple term, this explains socioeconomic inequality in LBW by using a set of determinants that vary consistently by wealth [22].

The analyses were performed in Stata version 15 and sample weight was considered, taking account on multistage cluster sampling design of the survey.

${ }^{1}$ Urban sector is comprised of areas administered by municipal and urban councils; the estate sector is predominantly concentrated in the tea plantation areas, while the rural sector comprises the areas that are not captured by the urban and estate sectors.

\section{Results}

Description of the Sample

The mean birth weight of the infants was reported as 2,917 grams and $16.9 \%$ of the infants were born with LBW. Mothers' mean age was reported as 31 years, and mean BMI and height recorded as $24 \mathrm{~kg} / \mathrm{m}^{2}$ and $153 \mathrm{~cm}$ respectively. Table 1 describes the key socioeconomic characteristics of the 7,713 children born in the 5 years preceding the survey and their their mothers. Nearly $44 \%$ of mothers had secondary education. The majority of mothers attended 5-7 antenatal care (ANC) visits during pregnancy (68.9\%), while almost $97 \%$ received Thriposha. Nearly $95.4 \%$ babies were full term babies. A slight majority of children were male (51.3\%). The highest number of mothers were in the lowest household wealth quintile (24.6\%), whereas only 16.4 reported in the highest wealth quintile. Approximately 78\% of the mothers lived in rural areas and, of these, $18.8 \%$ lived in the Western province.

\section{Table 1. Socioeconomic and demographic characteristics of the final study sample, DHS 2016}

\begin{tabular}{|c|c|}
\hline Covariates & $\begin{array}{l}N=7,713 \\
\text { Frequency }\end{array}$ \\
\hline
\end{tabular}

\section{Maternal age in years}

$<19$

20-24

74

0.9

25-34

1,012

13.1

35-39

4,468

57.9

40 and over

21

Maternal Body Mass Index

BMI $<18.5$

BMI 18.5-24.9

BMI 25-29.9

BMI 30 and over

1,622

537

\section{Maternal height}

Short $<=145 \mathrm{~cm}$

Average 145.1-155 cm

545

7.0

4,198

54.4

Tall 155.1 and over

Gestational period in months Below 8 months

(Less than 37 weeks)

8-10 months (37-42 weeks)

Antenatal visits

$<=2$ times

1,378

17.8

3-4 times

9.5

5-7 times

737

68.9

8 and over

Sex of child

Male

Female $\begin{array}{ll}3,964 & 51.3 \\ 3,749 & 48.6\end{array}$ 


\begin{tabular}{|c|c|c|}
\hline \multicolumn{3}{|l|}{ Maternal education } \\
\hline No education & 60 & 0.7 \\
\hline Primary & 320 & 4.5 \\
\hline Secondary & 3,386 & 43.9 \\
\hline Passed grade G.C.E (O/L) & 1,741 & 22.5 \\
\hline Passed grade G.C.E (A/L) & 1,761 & 22.8 \\
\hline Degree and above & 445 & 5.7 \\
\hline Received Thriposha & $\mathrm{N}=6736$ & \\
\hline Yes & 6,528 & 96.9 \\
\hline No & 208 & 3.1 \\
\hline \multicolumn{3}{|l|}{ Birth interval } \\
\hline First birth & 3,011 & 39 \\
\hline$<24$ & 394 & 5.1 \\
\hline $24-47$ & 1,584 & 20.5 \\
\hline $48-59$ & 793 & 10.2 \\
\hline $60+$ & 1,931 & 25 \\
\hline \multicolumn{3}{|l|}{ Wealth index quintile } \\
\hline Lowest & 1,900 & 24.6 \\
\hline Secondary & 1,571 & 20.3 \\
\hline Middle & 1,460 & 18.9 \\
\hline Fourth & 1,514 & 19.3 \\
\hline Highest & 1,268 & 16.4 \\
\hline \multicolumn{3}{|l|}{ Residential sector } \\
\hline Urban & 1,247 & 16.1 \\
\hline Rural & 5,974 & 77.4 \\
\hline Estate & 492 & 6.3 \\
\hline \multicolumn{3}{|l|}{ Ethnicity } \\
\hline Sinhalese & 5,025 & 65.1 \\
\hline Sri Lanka Tamil & 1,564 & 20.2 \\
\hline Indian Tamil & 242 & 3.1 \\
\hline Sri Lanka Moor/Muslim & 857 & 11.1 \\
\hline Malay and Burgher & 25 & 0.32 \\
\hline \multicolumn{3}{|l|}{ Province } \\
\hline Western & 1,455 & 18.8 \\
\hline Central & 996 & 12.9 \\
\hline Southern & 923 & 11.9 \\
\hline Northern & 905 & 11.7 \\
\hline Eastern & 857 & 11.1 \\
\hline North-Western & 832 & 10.7 \\
\hline North-Central & 530 & 6.87 \\
\hline Uva & 543 & 7 \\
\hline Sabaragamuwa & 672 & 8.7 \\
\hline
\end{tabular}

\section{Results of the multivariate linear regression model on birth weight}

According to the results presented in Table 2, after adjusting all covariates, maternal height, body mass index (BMI), gestational age (in months), birth interval, number of antenatal care visits, sex of the child, wealth, ethnicity and the province were statistically significant.

The coefficient for gestational age indicates that for every additional month in gestation, birth weight can be expected to increase by an average of 587 grams. The coefficient for BMI and height were also significant in the model. Male children are approximately 68 grams lighter than female babies in the sample. The model also highlighted the importance of attending antenatal clinics and birth intervals on determining birth weight $(p<0.001)$.

After controlling for other variables, maternal education level was not significant in the model. The relationship between birthweight and wealth is pronounced: mothers in the highest wealth quintiles have babies who weigh nearly 113 grams more than the babies of mothers in the lowest wealth quintiles. Ethnicity was found to be a crucial factor in determining birth weight: babies born to mothers of Indian Tamil ethnicity are 147 grams lighter (on average) than the other children in other ethnicities. Residential sector was not significant once ethnicity was added in to the model and it was henceforth removed from the model.

Some provinces such as Northern and Sabaragamuwa appeared to be significantly associated with birth weight. It can be concluded that in addition to maternal variables, being in the second and highest wealth quintiles and being an Indian Tamil in the Sabaragamuwa and Northern provinces are significantly associated with birth weight. The R2 value of the model was reported as 0.16 , showing 16 per cent of the variability in birth weight data is accounted from the covariates in the model.

Maternal age ( $p=0.47)$ and Thriposha consumption $(p=0.11)$ were not significantly associated with birth weight, hence these variables have been removed from the final model.

\section{Results of concentration curves, concentration indexes and decomposition as measures of inequalities}

The extent of the wealth-related inequality in prevalence of LBW was measured using concentration curves (CC) and concentration indexes (CI).

CC is an illustration of the cumulative percentage of LBW on the y axis and cumulative percentage of the population ranked by wealth index on the $x$ axis. The $45^{\circ}$ line represents perfect equality. If the curve lies below the line, the LBW is more concentrated among rich population, and if it lies above the line, the outcome is more concentrated among the lower SES individuals in the population [21,22]. The CI measures the magnitude of inequality, which is the twice the area between the concentration curve and the line of perfect equality. The calculation of CI is mentioned in elsewhere [21]. CI ranges between -1 and 1 ; a negative value denotes the pro-poor inequality; whereas, a positive value indicates the opposite (pro-rich inequality). A zero value represents perfect equality [21,22]. In our study, results show a CI of -0.13 (95\% Ci (confidence interval) $(-0.15$ to $-0.10, \mathrm{p}<0.001$ ) suggesting $\mathrm{LBW}$ is concentrated among the poorest households (Figure 2). [23] 
Table 2. Results of the stepwise backward multivariate linear regression models on birth weight

\begin{tabular}{|c|c|c|}
\hline \multirow[t]{2}{*}{ Covariates } & \multicolumn{2}{|c|}{ Maternal socioeconomic and residential covariates } \\
\hline & Coefficient & 95\% Confidence Interval \\
\hline Maternal Body Mass Index & $13.0^{* * *}$ & $(10.1,15.8)$ \\
\hline Maternal height (cm) & $11.0^{* * *}$ & $(8.8,13.2)$ \\
\hline \multicolumn{3}{|c|}{ Gestational period in months (ref. $<8$ months) } \\
\hline 8-10 months & $587.7^{* * *}$ & $(515.1,660.3)$ \\
\hline Antenatal visits & $15.6^{* * *}$ & $(10.3,20.8)$ \\
\hline \multicolumn{3}{|l|}{ Birth interval (ref. first birth) } \\
\hline$<24$ & 49.8 & $(-80.0,179.7)$ \\
\hline $24-47$ & $126.8^{* * *}$ & $(87.6,166.0)$ \\
\hline $48-59$ & $73.9^{* * *}$ & $(47.5,100.2)$ \\
\hline $60+$ & $48.8^{* * *}$ & $(22.4,75.2)$ \\
\hline Child is male (ref: female) & $-68.5^{* * *}$ & $(-92.8,-44.1)$ \\
\hline \multicolumn{3}{|c|}{ Maternal education (ref: Degree and above) } \\
\hline No education & -24.4 & $(-206.9,-158.1)$ \\
\hline Primary & -88.5 & $(-183.4,-6.4)$ \\
\hline Secondary & -51.2 & $(-114.9,-12.4)$ \\
\hline Passed G.C.E (O/L) & -57.7 & $(-122.2,-6.8)$ \\
\hline Passed G.C.E (A/L) & -45.7 & $(-107.9,-16.5)$ \\
\hline \multicolumn{3}{|c|}{ Wealth index quintile (ref. lowest) } \\
\hline Secondary & 37.1 & $(-1.3,-75.4)$ \\
\hline Middle & $48.9^{*}$ & $(7.8,90.0)$ \\
\hline Fourth & $77.8^{* * *}$ & $(34.6,121.1)$ \\
\hline Highest & $113.1^{* * *}$ & $(63.3,162.9)$ \\
\hline \multicolumn{3}{|l|}{ Ethnicity (ref. Sinhalese) } \\
\hline Sri Lankan Tamil & 39.5 & $(-8.1,87.2)$ \\
\hline Indian Tamil & $-147.6^{* *}$ & $(-241.6,-53.5)$ \\
\hline Sri Lanka Muslims & 24.1 & $(-23.7,71.9)$ \\
\hline Malay and Burgher & -61.4 & $(-273.3,151.1)$ \\
\hline \multicolumn{3}{|l|}{ Province (ref. Western) } \\
\hline Central & -8.5 & $(-57.4,40.3)$ \\
\hline Southern & 1.8 & $(-40.4,44.1)$ \\
\hline Northern & $42.5^{* *}$ & $(-23.2,108.3)$ \\
\hline Eastern & -52.8 & $(-103.3,-2.3)$ \\
\hline North-Western & -10.7 & $(-53.9,32.5)$ \\
\hline North-Central & -66.4 & $(-121.5,-11.3)$ \\
\hline Uva & 7.3 & $(-46.4,61.1)$ \\
\hline Sabaragamuwa & $-105.4^{* *}$ & $(-158.5,-52.2)$ \\
\hline $\mathbf{R} 2$ & 0.16 & \\
\hline Constant & 200.97 & $(34.8,684.4)$ \\
\hline
\end{tabular}

${ }^{*} \mathrm{P}<0.05{ }^{* *} \mathrm{P}<0.01{ }^{* * *} \mathrm{P}<0.001$ 


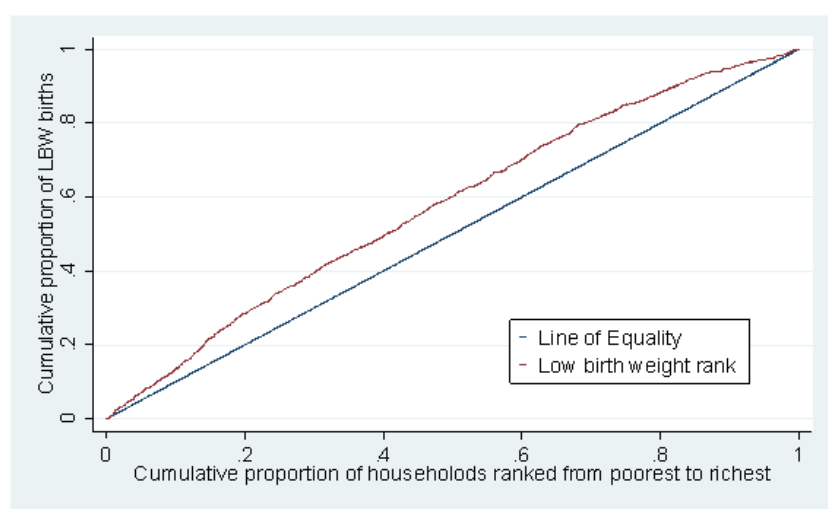

Figure 2. Concentration curves of LBW, considering the cumulative proportion of households ranked poorest to the highest.
We then investigated the difference in inequality of LBW by residential sector. Concentration indexes suggest that socioeconomic inequality of LBW was more than two times higher in the urban sector compared to estate areas. The rural sector reported the highest income inequality in child LBW compared to other counterparts (Appendix 1)

We then examined the contribution of each determinant to socioeconomic-related inequality in birth weight. Higher value percentages of contribution indicates the exacerbation of inequality and vise-versa. As shown in Table 3, maternal factors including BMI, maternal height and gestational weeks were responsible for nearly $37 \%$ of the total inequality. Foremost among maternal factors, maternal BMI is pronounced at $23.8 \%$. Maternal education explained $27.3 \%$ while ethnicity totally contributed $12 \%$ of the inequality in low birthweight.

Table 3. Decomposition of inequality in child birthweight: elasticity, concentration index (Cl), absolute and percentage contribution (by individual and groups)

\begin{tabular}{|c|c|c|c|c|c|}
\hline Covariates & Elasticity & $\begin{array}{c}\text { Contribution } \\
\text { Index }\end{array}$ & $\begin{array}{c}\text { Absolute } \\
\text { Contribution } \\
\text { (\%) }\end{array}$ & $\begin{array}{c}\text { Percentage } \\
\text { Concentration } \\
(\%)\end{array}$ & \\
\hline Maternal Body Mass Index & 0.129813 & 0.02195 & 0.00285 & 23.85 & 23.85 \\
\hline Maternal height (cm) & 0.540958 & 0.00284 & 0.00153 & 12.88 & 12.88 \\
\hline Antenatal visits & 0.013423 & -0.01846 & -0.00024 & -2.07 & -2.07 \\
\hline Gestational months (ref. $<8$ months) & 0.17945 & 0.00103 & 0.00018 & 1.55 & 1.55 \\
\hline \multicolumn{6}{|l|}{ Birth interval (ref. first birth) } \\
\hline$<24$ months & 0.001166 & -0.00411 & $-4.80 \mathrm{E}-06$ & -0.04 & \\
\hline 24-47 months & 0.008484 & -0.00714 & $-6.06 \mathrm{E}-05$ & -0.50 & \\
\hline 48-59 months & 0.003344 & -0.03366 & -0.00011 & -0.94 & -3.57 \\
\hline $60+$ months & 0.004978 & -0.05015 & -0.00024 & -2.08 & \\
\hline Child is male (ref: female) & 0.010189 & 0.00483 & $4.92 \mathrm{E}-05$ & 0.41 & 0.41 \\
\hline \multicolumn{6}{|l|}{ Maternal education (Ref: Degree \& above) } \\
\hline No school & -0.00028 & -0.66476 & 0.00018 & 1.53 & \\
\hline Primary & -0.00203 & -0.56633 & 0.00115 & 9.63 & \\
\hline Secondary & -0.0123 & -0.21690 & 0.00266 & 22.33 & 27.39 \\
\hline Passed G.C.E. (O/L) & -0.00451 & 0.03704 & -0.00016 & -1.39 & \\
\hline Passed G.C.E. (A/L) & -0.00159 & 0.35441 & -0.00056 & -4.70 & \\
\hline \multicolumn{6}{|l|}{ Ethnicity (ref. Sinhalese) } \\
\hline Sri Lankan Tamils & -0.00025 & -0.40717 & 0.00010 & 0.85 & \\
\hline Indian Tamils & -0.00221 & -0.58664 & 0.00129 & 10.86 & 12.38 \\
\hline Muslims, Burgher \& Malay & 0.000656 & 0.12076 & 7.93E-05 & 0.66 & \\
\hline \multicolumn{6}{|l|}{ Province (ref. Western) } \\
\hline Central & -0.00113 & -0.07764 & $8.75 E-05$ & 0.73 & \\
\hline Southern & 0.00076 & 0.12763 & $9.70 \mathrm{E}-05$ & 0.81 & \\
\hline Northern & 0.00178 & -0.47603 & -0.00084 & -7.09 & -3.37 \\
\hline Eastern & -0.00137 & -0.10953 & 0.00014 & 1.25 & \\
\hline North-Western & 0.000221 & 0.03280 & 7.24E-06 & 0.06 & \\
\hline North-Central & -0.00072 & 0.08342 & $-5.99 \mathrm{E}-05$ & -0.50 & \\
\hline Uva & 0.000323 & -0.11811 & $-3.81 \mathrm{E}-05$ & -0.31 & \\
\hline Sabaragamuwa & -0.00262 & -0.07683 & 0.00020 & 1.68 & \\
\hline Residual (unexplained) & & & & 0.3053 & 30.5 \\
\hline Total & & & & & 100.0 \\
\hline
\end{tabular}


Other factors including gestational age, birth interval, sex of the child and the provinces had minimal or no contribution in explaining inequality in birth weight. There was $30.5 \%$ of unexplained variance (residual term) in the regression model that could be claimed due to the effect of wealth and other factors not included in the decomposition.

\section{Discussion and conclusion}

This study clearly demonstrates that maternal factors such as maternal BMI, gestational months and birth interval have a very strong influence on birth weight.

Agreeing with previous studies, the risk of having an infant with low birth weight was significantly associated with women with low maternal BMI and short stature $[24,27]$. Maternal BMI is reflective of nutritional status and an insufficient food supply during pregnancy can place a mother and her fetus at risk.

Therefore, this highlights the importance of implementing relevant targeted health intervention to improve the nutritional status of mothers during pregnancy. The government in Sri Lanka has launched programs such as free distribution of "Thriposha”, especially targeting poor families. However, confirming previous findings $[23,24]$, the current study also highlights that the effectiveness of this program is questionable in terms of addressing the nutritional needs of mothers. This may due to an inability to identify the true recipients of "Thriposha” or those sharing rather than consuming it. Thriposha only fulfils nearly $400 \mathrm{kcal}$ [25], which may not adequately address the nutritional deficiencies of pregnant mothers. Therefore, the government could introduce a new alternative food supplement containing nutrients of more than $1000 \mathrm{kcal}$ per day for pregnant women with low BMI.

ANC care in Sri Lanka is mainly integrated with maternal and child health services to provide antenatal, intrapartum and postnatal care for mothers. Supporting previous findings, this study found that a lack of ANC visits is associated with low mean birth weight.

In addition to maternal factors, this study revealed that wealth and being of Indian Tamil ethnicity are influential factors in determining birth weight. Regression analysis suggests that mothers living in poor households were more prone to have children with low mean birth weight than mothers from richer households. This is potentially compounded by the fact that socio-economic status may be a barrier to good nutrition and the receipt of ANC visits during pregnancy.

This study found that maternal educational level has no significant relationship with the average level of birth weight. Further, no statistically significant differences were evident for birth weight and residential sector, after controlling for ethnicity in the model. It may be that the majority of Indian Tamils represent the estate sector and the total number of Estate Indian Tamil births are less representative compared to the other sectors.

The significant risk to Indian Tamil mothers in the estate sector of having a low birth weight child further remains agreeing with previous literature not showing a considerable increase in birth weight. [23,24,27]. This could perhaps be attributed to the genetic tendency for downregulation of fetal growth explained across the generation of Asian women migrants in UK [24, 26]. Sri Lankan Estate Indian Tamils, who descended from South Indian Tamils, migrated to Sri Lanka to work as estate laborers in the plantation sector in the 19th century [24,27]. These people were drawn from the most depressed, poorest and lowest caste group in South India. Hence, genetic factors may affect the persistent LBW among these people [24]. Since, there is no data capturing genetic factors, proper mechanisms should be taken to monitor the contribution of such factors among population groups.

Findings of the study also confirmed that socioeconomic inequality exists, and from the negative value of CI reflects that the LBW was higher among children of poorer households; correspond with previous studies conducted in Sri Lanka [24, 27]. The value -0.13 remains constant even after a decade, (DHS, 2016) [23,24], however, there is a caution comparing CI values over time due to measurement incomparability, such as restricted birth weight and island-wide coverage of data of the present study. The findings also consistent with the evidence from other developing countries such as China and Iran that LBW inequalities exist among mothers with low socioeconomic status [28, 29].

From the decomposition results, BMI, maternal height and gestational weeks, maternal education and ethnicity were found contributing to birth weight inequalities. From the unobserved residuals, it can be assumed that wealth accounted for socioeconomic inequality in birth weight. This reveals that poverty can be caused towards the inequality in birth weight in Sri Lanka.

Therefore, this study emphasizes the essentiality of initiating multi-faceted approaches, particularly to address the nutritional needs of mothers. Further, relevant interventions to improve the socioeconomic status of women should be taken focusing on vulnerable populations in the estate sector and ethnic minorities.

\section{Acknowledgement}

Authors would like to thank Department of Census and Statistics, Sri Lanka for granting permission to access the DHS data. 
Appendix 1. Concentration index for each residential sector

\begin{tabular}{llll}
\hline Residential sector & CI & $\begin{array}{l}\text { Standard } \\
\text { Error }\end{array}$ & $\begin{array}{l}\text { Confidence } \\
\text { Interval }\end{array}$ \\
\hline Urban Sector & -0.078 & 0.045 & $-.169,0.125$ \\
Rural Sector & $-.122 * * *$ & 0.017 & $-.157,-.088$ \\
Estate Sector & -0.032 & 0.045 & $-0.121,0.055$ \\
\hline
\end{tabular}

\section{References}

1. WHO, Guidelines on Optimal Feeding of Low Birth-Weight Infants in Low- and Middle-Income Countries. 2011.

2. WHO, Global Nutrition Targets 2025: Low Birth Weight Policy Brief 2014.

3. Hack M, NK Klein, HG. Taylor, Long-term developmental outcomes of low birth weight infants. Future Child 1995. 5(1): 176-96.

4. Negrato, C.A. and M.B. Gomes, Low birth weight: causes and consequences. Diabetology and Metabolic Syndrome 2013; 5: 49.

5. Khan A,Nasrullah FD, Jaleel R. Frequency and risk factors of low birth weight in term pregnancy. Pakistan Journal of Medical Sciences 2016; 32(1): 138-42.

6. Kramer MS. Determinants of low birth weight: methodological assessment and meta-analysis. Bull World Health Organ 1987; 65(5): 663-737.

7. Calkins K, Devaskar SU. Fetal origins of adult disease. Current problems in pediatric and adolescent health care, 2011; 41(6): 158-76.

8. Doherty T, Kinney M. Low birthweight: will new estimates accelerate progress? The Lancet Global Health 2019; 7(7): e809-e810.

9. Bian Y, et al. Maternal risk factors for low birth weight for term births in a developed region in China: a hospital-based study of 55,633 pregnancies. J Biomed Res. 2013; 27(1): 14-22.

10. Dahlui M, et al. Risk factors for low birth weight in Nigeria: evidence from the 2013 Nigeria Demographic and Health Survey. Global Health Action 2016; 9: 28822.

11. Kader M, Perera NK. Socio-economic and nutritional determinants of low birth weight in India. $N$ Am J Med Sci. 2014; 6(7): 302-8.

12. Van Deutekom AW, et al. The Association of Birth Weight and Infant Growth with Energy Balance-Related Behavior - A Systematic Review and Best-Evidence Synthesis of Human Studies. PloS One 2017; 12(1): e0168186.

13. Jananthan R, Wijesinghe DGNG, Sivananthawerl $\mathrm{T}$. Maternal Anthropometry as a Predictor of Birth Weight. 2010.

14. Perera P, et al. Growth parameters at birth of babies born in Gampaha district, Sri Lanka and factors influencing them.
WHO South-East Asia Journal of Public Health 2013; 2(1): 57-62.

15. WHO. Sri Lanka: WHO statistical profile. Country statistics and global health estimates by WHO and UN partners 2015; Available from: http://www.who.int/gho/countries/ lka.pdf?ua=1.

16. World Bank, Sri Lanka Attaining the Millennium Development Goals in Sri Lanka. 2015.

17. UN. Free Health Policy in Sri Lanka. 2016 [cited 2018 18]; Available from: http://lk.one.un.org/7060/en/free-healthpolicy-in-sri-lanka.

18. Department of Census and Statistics, Sri Lanka Demographic and Helath Survey. 2016.

19. Ministry of Health Nutrition and Indigenous Medicine, Annual Health Bulletin Sri Lanka. 2015, Ministry of Health, Nutrition and Indigenous Medicine: Colombo.

20. UNICEF, Nutritional status in Sri Lanka, determinants and interventions: a desk review. 2011.

21. O’Donnell O, et al. Decomposition of Inequalities in Health and Health Care 2006; 179-92.

22. Pulok MH, Sabah MNU, Enemark U. Socioeconomic inequalities of child malnutrition in Bangladesh. International Journal of Social Economics 2006; 43(12): 1439-59. DOI: https://doi.org/10.1108/IJSE-03-2015-0065

23. Abeywickrama G, Padmadas S, Hinde A. Social inequalities in low birthweight outcomes in Sri Lanka: evidence from the Demographic and Health Survey 2016. BMJ Open. 2020; 10(5): e037223. Retrieved from: http://bmjopen. bmj.com/content/10/5/e037223.abstract

24. Anuranga C, Wickramasinghe R, Rannan-Eliya RP, Hossain S, Abeykoon A. Trends, inequalities and determinants of low birth weight in Sri Lanka. Ceylon Medical Journal 2012; 57(2): 61-9. DOI:http://doi.org/10.4038/cmj.v57i2.4429

25. Sri Lanka Thriposha Ltd, S.L.T. Nutrient Content. 2016 [cited 2019 20.08.2019]; Available from: http:// www.thriposha.lk/thriposha-production/nutrient-content/

26. Leon DA, KA. Moser, Low birth weight persists in South Asian babies born in England and Wales regardless of maternal country of birth. Slow pace of acculturation, physiological constraint or both? Analysis of routine data. J Epidemiol Community Health 2012; 66(6): 544-51.

27. Jayawardena P. Soico-Economic Determiants and Inequalities in Child Malnutrtion in Sri Lanka. Well-Being and Social Policy Journal 2012; 8: 1-22.

28. Pei L, et al. Changes in Socioeconomic Inequality of Low Birth Weight and Macrosomia in Shaanxi Province of Northwest China, 2010-2013: A Cross-sectional Study. Medicine 2016; 95(5): e2471.

29. Almasi-Hashiani A, Sepidarkish M, Safiri S, et al. Understanding determinants of unequal distribution of stillbirth in Tehran, Iran: a concentration index decomposition approach. BMJ Open 2017; 7: e013644. DOI:10.1136/ bmjopen-2016-013644 